\title{
Study of Polyolefin Gel in Organic Solvents VIII. Size of Crystalline Junction and Structure of Ethylene-Propylene Random Copolymer $\mathrm{Gel}^{\dagger}$
}

\author{
Masaru OKabe, Yoshihiro Moteki, ${ }^{*}$ Hironori UranaKa, ${ }^{* *}$ \\ Masato TAKAHASHI, ${ }^{* *}$ and Hideomi MATSUdA ${ }^{* *}$ \\ Department of Chemical Technology, Faculty of Engineering, \\ Kanagawa Institute of Technology, 1030, Shimo-ogino, \\ Atsugi, Kanagawa 243-02, Japan \\ * Kawasaki Plastics Laboratory, Showa Denko Co., \\ 3-2, Chidori-cho, Kawasaki-ku, Kawasaki, \\ Kanagawa 210, Japan \\ ** Department of Fine Materials Engineering, Faculty of Textile Science \\ and Technology, Shinshu University, \\ 3-15-1, Tokida, Ueda, Nagano 386, Japan
}

(Received February 8, 1993)

\begin{abstract}
Gel-melting temperatures $\left(T_{\mathrm{m}}^{\mathrm{g}}\right)$ of ethylene-propylene random copolymer gels formed in $n$-hexane and $n$-octane were measured as a function of polymer concentration. The copolymers were heterogeneous in both composition and molecular weight. $T_{\mathrm{m}}^{\mathrm{g}}$ obeyed well the thermodynamic theory derived by Takahashi, in which gel $\rightarrow$ sol transition was treated as melting of crystalline junctions with fringed micelle-type morphology: Plots of $1 / T_{\mathrm{m}}^{\mathrm{g}} v s . \ln V_{2} N$ according to the theory were scaled on a common straight line when copolymers had similar propylene contents $(P C)$, where $V_{2}$ is the volume fraction of the copolymer in the gel and $N$ is the weight-average degree of polymerization. Quantitative analysis of the theory, including measurements of dilute solution properties, led to the results that average size of crystalline junction $\zeta$ in number of ethylene units per crystalline sequence was $c a$. 11 for copolymers with $P C=22 \mathrm{wt} \%, 9$ for $P C=26$ and $27 \mathrm{wt} \%$, and 5 for $P C=49 \mathrm{wt} \%$, and thus $\zeta$ decreased with increasing $P C$. The junction sizes $\zeta$ were reasonable order as compared with those estimated from X-ray diffractions.

KEY WORDS Thermoreversible Gel / Ethylene-Propylene Random Copolymer / Gel-Melting Temperature / Structure of Gel / X-Ray Diffraction / Junction Size /
\end{abstract}

An ethylene-propylene (EP) copolymer with suitable content of propylene units shows rubber-like properties and thus the copolymer has been utilized as an elastomer. ${ }^{1}$ It is well known that an EP block copolymer is synthesized with a titanous catalyst system, whereas a copolymer with random composition of ethylene and propylene is obtained with a vanadous catalyst system. Thermal property and crystallinity in bulk or single-crystal of EP copolymer have been studied as a function of propylene content as well as propylene distribution (i.e., block or random placement of methyl branches) by many workers. ${ }^{2-7}$ Strate et al ${ }^{1,8,9}$ reported from accurate X-ray diffraction measurements of bulk EP copolymer including $\mathrm{ca} .40 \mathrm{~mol} \%$ of propylene units randomly, whose bulk was annealed for several days, that folded lamella could not be crystallized in such copolymer including high

${ }^{\dagger}$ Presented in part at the 41st Polymer Symposium of the Society of Polymer Science, Japan, September 1992 [Polym. Prepr. Jpn., 41, 3216 (1992)]. 
content of propylene but fringed micelle crystallite might be most appropriate morphology in the bulk.

An EP copolymer widely varies from crystalline to noncrystalline depending on content of propylene units: The copolymer is crystalline if the propylene content is a little; When many propylene units (ca. $20-50 \mathrm{~mol} \%$ ) are included randomly along copolymer chains, it becomes noncrystalline because methyl branches along polyethylene backbone chains disturb considerably crystallization. That is, by introducing the methyl branches, they are incorporated into a crystalline lattice of polyethylene expanding the dimensions of the orthorhombic unit cell (particularly the $a$ dimension) and, as a result, regularity of the lattice begins to be destroyed. ${ }^{10}$

In the previous studies of this series, gel-melting temperatures $T_{\mathrm{m}}^{\mathrm{g}}$ of highly crystalline polyolefins such as isotactic polypropylene (iPP), ${ }^{11 a}$ linear high-density polyethylene (LHDPE), ${ }^{11 \mathrm{~b}}$ linear low-density polyethylene (LLDPE), ${ }^{11 \mathrm{c}}$ and branched lowdensity polyethylene (BLDPE) ${ }^{11 d}$ in many organic solvents (such as tetralin, decalin,

\section{Gel-Melting Temperatures}

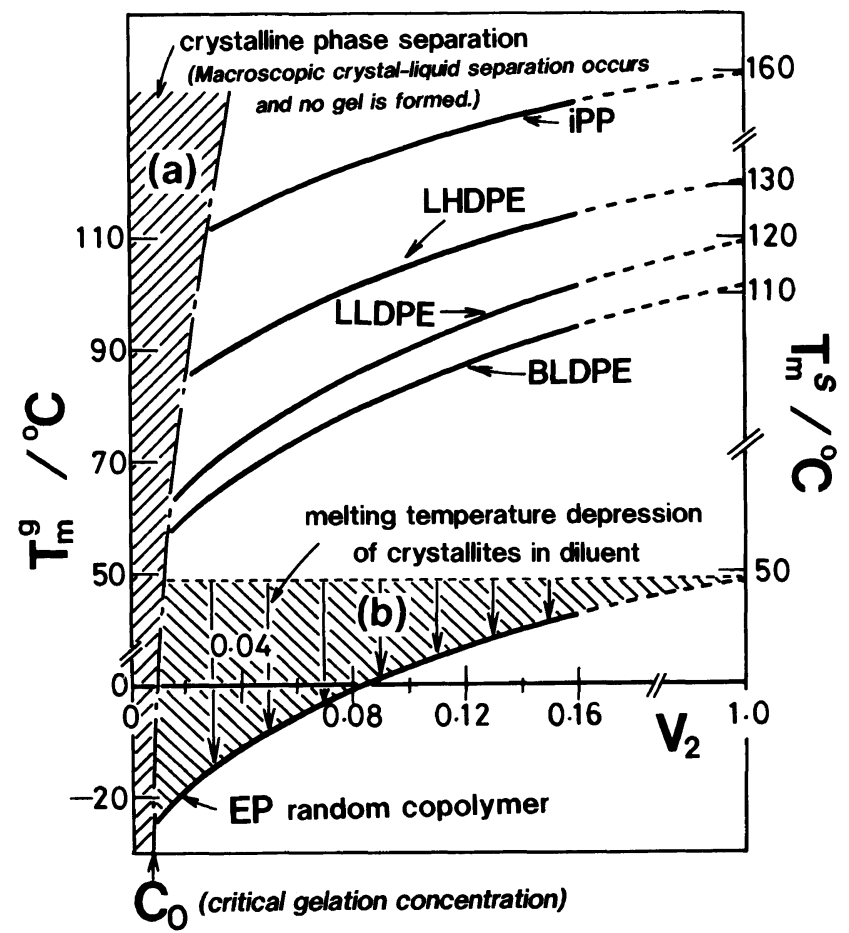

(A)

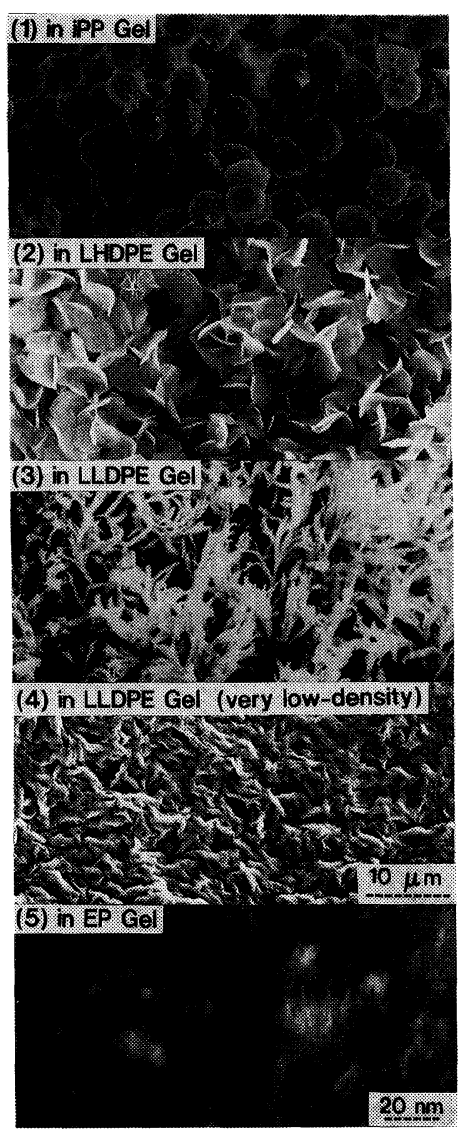

(B)

Figure 1. Schematic diagram between gel-melting temperature $\left(T_{\mathrm{m}}^{\mathrm{g}}\right)$ curves measured for various polyolefin-toluene gels and volume fraction $V_{2}$ of polymer in gel (A), and morphologies of crystallites formed in the polyolefin gels (B), which were observed by an electron microscope. $T_{\mathrm{m}}^{\mathrm{s}}$ in the graph (A) is the melting temperature of sample. Magnification in each photograph (B) of (1), (2), and (3) is the same as that in (4). 
xylene, toluene, benzene, and carbon disulfide) have been measured as a function of polymer concentration. The relationship is illustrated schematically in Figure 1(A). $T_{\mathrm{m}}^{\mathrm{g}}$ of each polymer increases monotonously with increasing volume fraction $V_{2}$ of the polymer in the gel, and rises in the order: BLDPE $<$ LLDPE $<$ LHDPE $<$ iPP. This order corresponds to that of melting temperature $T_{\mathrm{m}}^{\mathrm{s}}$ of each solid sample. Crystallites formed in these gels, which are junction points of the network structure, are spherulitic for iPP gel, plate-like (lamellar) for LHDPE gel, and dendritic or noodle-like (very low-density copolymer with comonomer of 1-butene randomly) for LLDPE gel as shown in Figure 1(B).

Recently, we also reported that EP random copolymers in carbon disulfide, toluene, and cyclopentane converted to thermally reversible gels when solutions were cooled from $c a .-40$ to $-70^{\circ} \mathrm{C} .{ }^{12} T_{\mathrm{m}}^{\mathrm{g}}$ of EP gel lowered considerably in comparison with that of iPP, LHDPE, LLDPE, or BLDPE gel as seen in Figure 1(A). In that study, it was suggested from measurements of X-ray diffraction, atomic force microscope, and transmission electron microscope that fringed micelle-type junctions were formed in EP gels. Moreover, melting behavior of the gels obeyed well the Takahashi theory, ${ }^{13,14}$ in which junction point of a copolymer-diluent gel system is modelled as a fringed micelle morphology. As the Takahashi theory was found to be applicable to $T_{\mathrm{m}}^{\mathrm{g}}$ of EP random copolymer gels, effect of the content of propylene units on $T_{\mathrm{m}}^{\mathrm{g}}$ was examined qualitatively in the previous study ${ }^{12}$ with the aid of the theory.

In this study, gel-melting temperatures of EP random copolymer gels formed in $n$-hexane and in $n$-octane are measured successively from the previous study. Then, the quantitative analysis of the EP gels is carried out: The size of crystalline junction is estimated by using the Takahashi theory, whose size is compared with that estimated from $\mathrm{X}$-ray diffraction measurements. Another purpose of this study is to estimate the end interfacial free energy of the crystalline junction.

\section{EXPERIMENTAL}

\section{Materials}

Seven samples of EP random copolymer, supplied by Japan Synthetic Rubber Co., were

Table I. Physical properties of EP samples ${ }^{\mathrm{a}}$

\begin{tabular}{|c|c|c|c|c|c|c|c|c|}
\hline \multirow{3}{*}{ Sample } & \multirow{2}{*}{\multicolumn{2}{|c|}{ From GPC data }} & \multirow{2}{*}{\multicolumn{2}{|c|}{$\begin{array}{c}\text { From IR data } \\
\qquad P C\end{array}$}} & \multicolumn{4}{|c|}{ From DSC data } \\
\hline & & & & & \multirow{2}{*}{$\begin{array}{r}T_{\mathrm{g}} \\
{ }^{\circ} \mathrm{C}\end{array}$} & \multirow{2}{*}{$\frac{T_{\mathrm{m}}^{\mathrm{s}}}{{ }^{\circ} \mathrm{C}}$} & \multirow{2}{*}{$\frac{\Delta H_{\mathrm{m}}^{\mathrm{s}}}{\mathrm{Jg}^{-1}}$} & \multirow{2}{*}{$\frac{X_{\mathrm{c}}}{\%}$} \\
\hline & $\bar{M}_{w} \times 10^{-4}$ & $\mathrm{~N}$ & wt $\%$ & $\mathrm{~mol} \%$ & & & & \\
\hline EP-17 & 17.1 & 5781 & 22 & 16 & -51.4 & 49.1 & 14.37 & 5.0 \\
\hline EP-19 & 19.0 & 6423 & 22 & 16 & -50.1 & 48.4 & 13.24 & 4.6 \\
\hline EP-21 & 21.2 & 7167 & 22 & 16 & -49.7 & 49.3 & 16.45 & 5.7 \\
\hline EP-22 & 21.5 & 7192 & 26 & 19 & -55.9 & 47.5 & 3.88 & 1.3 \\
\hline EP-28 & 28.2 & 9399 & 27 & 20 & -57.8 & 45.8 & 3.64 & 1.3 \\
\hline EP-35 & 35.0 & 11666 & 27 & 20 & -57.4 & 44.2 & 1.60 & 0.55 \\
\hline EP-38 & 37.7 & 11713 & 49 & 39 & -66.5 & - & - & - \\
\hline
\end{tabular}

a $\bar{M}_{w}$, weight-average molecular weight determined by GPC; $N$, weight-average degree of polymerization calculated from $\bar{M}_{w}$ and PC $[\mathrm{mol} \%] ; P C$, propylene content estimated by IR; $T_{\mathrm{g}}$ and $T_{\mathrm{m}}^{\mathrm{s}}$, glass transition temperature and melting temperature (endothermic peak temperature) measured by DSC at a heating rate of $10^{\circ} \mathrm{C} \mathrm{min}^{-1} ; \Delta H_{\mathrm{m}}^{\mathrm{s}}$, heat of fusion; $X_{c}$, degree of crystallinity calculated from eq 1. 
used. These copolymers are heterogeneous in both composition and molecular weight. The ratio of propylene to ethylene in all of the copolymers was determined by infrared spectroscopy (IR). Physical properties of the samples are shown in Table I.

Weight-average molecular weight $\bar{M}_{w}$ changes from $17.1 \times 10^{4}$ to $37.7 \times 10^{4}$, whereas propylene content (PC) varies from 22 to $49 \mathrm{wt} \%$. The samples were purified by the method described in the previous study. ${ }^{12}$ Degree of crystallinity $X_{\mathrm{c}}$ listed in Table I was estimated from differential scanning calorimetry (DSC) using the following equation ${ }^{15}$ :

$$
X_{\mathrm{c}}=\left[\Delta H_{\mathrm{m}}^{\mathrm{s}} / \Delta H_{\mathrm{m}}^{*}\right] \times 100
$$

where $\Delta H_{\mathrm{m}}^{\mathrm{s}}$ and $\Delta H_{\mathrm{m}}^{*}$ are the heats of fusion for present copolymer and for perfectly crystalline polyethylene, respectively. A Shimadzu heat flux differential scanning calorimeter, Model DSC-50, equipped with the thermal analysis data system for the base line correction, transition temperature, and calculation of the transition heat, was used for measurements of $\Delta H_{\mathrm{m}}^{\mathrm{s}}$ after calibrating with standard indium $\left(T_{\mathrm{m}}=156.6^{\circ} \mathrm{C} ; \Delta H_{\mathrm{f}}=28.45\right.$ $\mathrm{J} \mathrm{g}^{-1}$ ). A value of $289 \mathrm{~J} \mathrm{~g}^{-1}$ was used for $\Delta H_{\mathrm{m}}^{*}$ in this study, which was estimated by Wunderlich et al.$^{16} \mathrm{It}$ is obvious in Table I that $X_{\mathrm{c}}$ decreases (i.e., copolymer changes to noncrystalline) with increasing $P C$. The heat effect in EP-38 with $P C=49 \mathrm{wt} \%$ was too small for an endothermic peak to be distinguished from a change in base line.

$n$-Octane $\left(\mathrm{mp}=-56.8^{\circ} \mathrm{C} ; \mathrm{bp}=125.7^{\circ} \mathrm{C}\right)$ and $n$-hexane $\left(\mathrm{mp}=-95.3^{\circ} \mathrm{C} ; \mathrm{bp}=68.7^{\circ} \mathrm{C}\right)$ were used as solvents for gelation, and purified by distillation before use.

\section{Preparation Method of Gel and Measurements of Gel-Melting Temperature $T_{\mathrm{m}}^{\mathrm{g}}$}

A definite amount of sample was dissolved completely in a solvent in a sealed glass tube with $c a .35 \mathrm{~cm}$ length and $1 \mathrm{~cm}$ diameter. Then, the sample tube was immersed in a well-stirred methanol bath kept at $-40^{\circ} \mathrm{C}$ for $1 \mathrm{~h}$ to prepare a gel. All of solutions with higher concentration than $c a .1 \mathrm{~g} / 100 \mathrm{~cm}^{3}$ converted to thermally reversible gels on cooling and the gels exhibited turbidity. The degree of turbidity decreased with increasing $P C$ of the sample. In a dilute polymer solution, however, all systems did not turn into gels but crystal-liquid phase separation occurred macroscopically.

Gel-melting temperature $T_{\mathrm{m}}^{\mathrm{g}}$ was measured by the falling-ball method ${ }^{17}$ using a steel ball of ca. $30 \mathrm{mg}$ weight with $2 \mathrm{~mm}$ diameter. In case of $30 \mathrm{mg}$ weight steel ball, effect of the weight of steel ball on $T_{\mathrm{m}}^{\mathrm{g}}$ was eliminated. A gel was heated from $-40^{\circ} \mathrm{C}$ at a rate of $c a$. $0.3^{\circ} \mathrm{C} \mathrm{min}^{-1}$, and $T_{\mathrm{m}}^{\mathrm{g}}$ was determined similarly to the previous study. ${ }^{12}$

\section{Osmotic Pressure Measurements}

In case of estimating the end interfacial free energy $\sigma_{\mathrm{ec}}$ of crystalline junctions in an EP gel from the Takahashi theory, value of the cohesive energy density $B^{\prime}$ is necessary. In this study, $B^{\prime}$ was evaluated from osmotic pressure measurements using the following relation$\operatorname{ship}^{18}$ :

$$
\chi_{1}=\frac{B^{\prime} V_{1}}{R T}
$$

where $\chi_{1}$ is the Flory-Huggins interaction parameter between polymer and solvent, $R$ is the gas constant, and $V_{1}$ is the molar volume of the solvent.

Osmotic pressure measurements were carried out in toluene, $n$-hexane, and $n$-octane at $35 \pm 0.001^{\circ} \mathrm{C}$ using a modified Zimm-Myerson type osmometer with gel cellophane membranes.

\section{$X$-Ray Diffraction Measurements}

In order to estimate the size of crystallite formed in an EP gel, X-ray diffraction measurements were carried out using a Philips X-ray diffractometer, Model PW-1840, with an experimental condition of $30 \mathrm{kV}$ and $30 \mathrm{~mA}$.

A dried gel film was used as the specimen of $\mathrm{X}$-ray diffraction. The film was prepared as 
follows: A molten gel was poured into a sample holder of the $\mathrm{X}$-ray apparatus and gelation was conducted at $-40^{\circ} \mathrm{C}$ for $1 \mathrm{~h}$ in the holder; Then, the gel was dried sufficiently under reduced pressure at $-40^{\circ} \mathrm{C}$ at which the gel did not melt in a solvent. A diffraction pattern of the dried gel film was recorded using nickel-filtered $\mathrm{Cu}-K_{\alpha}$ radiation with wavelength $\lambda=0.1541 \mathrm{~nm}$.

\section{RESULTS AND DISCUSSION}

\section{Gel-Melting Temperature $T_{\mathrm{m}}^{\mathrm{g}}$}

Relation between gel-melting temperature $T_{\mathrm{m}}^{\mathrm{g}}$ and polymer concentration $C$ in $n$-octane is shown in Figure 2. In any sample, $T_{\mathrm{m}}^{\mathrm{g}}$ increases logarithmically with increasing polymer concentration. The characteristic result in the figure is that seven samples are divided broadly into three groups according to $T_{\mathrm{m}}^{\mathrm{g}}$. That is, the highest $T_{\mathrm{m}}^{\mathrm{g}}$ group has propylene content $P C=22 \mathrm{wt} \%$, the middle group has

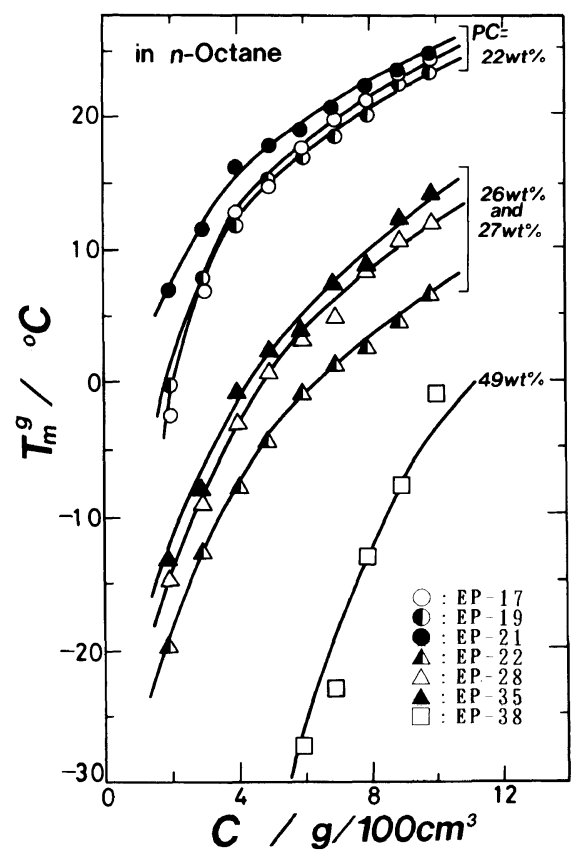

Figure 2. Relation between gel-melting temperature $T_{\mathrm{m}}^{\mathrm{g}}$ measured by the falling-ball method and polymer concentration $C$ in $n$-octane.
$P C=26$ and $27 \mathrm{wt} \%$, and the lowest $T_{\mathrm{m}}^{\mathrm{g}}$ sample has $P C=49 \mathrm{wt} \%$. Thus, $T_{\mathrm{m}}^{\mathrm{g}}$ lowers considerably with increasing $P C$, regardless of differences in molecular weights.

On the other hand, in a group with similar $P C$ (e.g., in EP-22, EP-28, and EP-35, where molecular weights $\bar{M}_{w}$ are different widely from one another), $T_{\mathrm{m}}^{\mathrm{g}}$ rises with increasing $\bar{M}_{w}$. Thus, the molecular weight dependence of $T_{\mathrm{m}}^{\mathrm{g}}$ appears. The above results lead to the facts that $T_{\mathrm{m}}^{\mathrm{g}}$ depends on polymer concentration, propylene content, and molecular weight. In particular, effect of the propylene content on $T_{\mathrm{m}}^{\mathrm{g}}$ is dominant. The same tendency was obtained for EP- $n$-hexane gels. So, the effect of propylene content on $T_{\mathrm{m}}^{\mathrm{g}}$ is examined in the following section using the Takahashi theory. It was already found in the previous study ${ }^{12}$ that the theory was applicable well to EP random copolymer-organic solvent gel systems.

\section{Effect of Propylene Content on $T_{\mathrm{m}}^{\mathrm{g}}$}

Takahashi and co-workers studied theoretically and experimentally many kinds of copolymer-diluent gel systems, ${ }^{14}$ and derived the thermodynamic theory for gel-melting temperatures of the copolymers from the melting temperature depression of crystallites in a diluent as formulated by Flory ${ }^{19}$ and

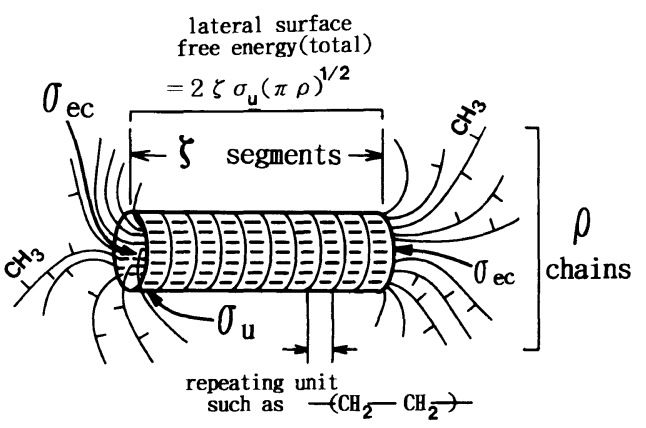

Figure 3. Schematic drawing of fringed micelle-type junction proposed by Takahashi ${ }^{13}: \zeta$, length of crystalline junction in number of ethylene units; $\sigma_{\mathrm{ec}}$, end interfacial free energy per crystalline sequence; $\sigma_{\mathrm{u}}$, lateral surface free energy per repeating unit; $\rho$, number of polymer chains which enter into the crystalline junction. 
Mandelkern, ${ }^{20}$ assuming the junction point of the copolymer gels to be a fringed micelle-type crystallite comprised of $\zeta$ segments in length and $\rho$ chains in cross section as illustrated schematically in Figure 3. This model is based upon the conjecture that noncrystalline sequences in a copolymer chain, such as chain branches by comonomer units or stereo-irregularities, become soluble parts in a gel, while crystalline sequences such as ethylene sequences form crystalline junctions of the gel network. In Figure 3, a cylindrical junction is shown but another type of junction such as rectangular or plate-like lamella is also available. The theory is written as follows ${ }^{13}$ :

$$
1 / T_{\mathrm{m}}^{\mathrm{g}}=A-B \cdot \ln V_{2} N
$$

with

$$
\begin{aligned}
A= & \frac{\zeta}{\zeta \Delta h_{\mathrm{u}}+\zeta B^{\prime} V_{\mathrm{A}}-2 \sigma_{\mathrm{ec}}} \\
& \times\left(\frac{\Delta h_{\mathrm{u}}}{T_{\mathrm{m}}^{0}}+\frac{R V_{\mathrm{A}}}{V_{1}}-R \cdot \ln X_{\mathrm{A}}\right) \\
B= & \frac{\zeta}{\zeta \Delta h_{\mathrm{u}}+\zeta B^{\prime} V_{\mathrm{A}}-2 \sigma_{\mathrm{ec}}}
\end{aligned}
$$

where $T_{\mathrm{m}}^{\mathrm{g}}[\mathrm{K}]$ is the observed gel-melting temperature, $\zeta$ is the number of repeating units per crystalline sequence (i.e., ethylene-unit length such as $\left[\mathrm{CH}_{2}-\mathrm{CH}_{2}\right]_{\zeta}$, which enters into the crystalline junction as sequence),
$\Delta h_{\mathrm{u}}\left[\mathrm{J} \mathrm{mol}{ }^{-1}\right]$ is the heat of fusion per repeating unit, $B^{\prime}\left[\mathrm{J} \mathrm{cm}^{-3}\right]$ is the cohesive energy density defined by eq $2, V_{1}$ and $V_{\mathrm{A}}\left[\mathrm{cm}^{3} \mathrm{~mol}^{-1}\right]$ are the molar volumes of the solvent and crystalline unit, respectively, $\sigma_{\text {ec }}\left[\mathrm{J} \mathrm{mol}^{-1}\right]$ is the end interfacial free energy per crystalline sequence, $T_{\mathrm{m}}^{0}[\mathrm{~K}]$ is the equilibrium melting temperature of perfectly crystalline homopolymer (polyethylene), $X_{\mathrm{A}}$ is the mole fraction of crystallizable unit in the copolymer chain, $V_{2}$ is the volume fraction of the copolymer in the gel, $R$ is the gas constant $\left(8.314\left[\mathrm{~J} \mathrm{~K}^{-1} \mathrm{~mol}^{-1}\right]\right)$, and $N$ is the weight-average degree of polymerization.

Gel-melting temperatures of the present EP gels were analyzed by using eq 3 . According to the equation, plots of $1 / T_{\mathrm{m}}^{\mathrm{g}}\left[\mathrm{K}^{-1}\right] v s . \ln V_{2} N$ are expected to yield a straight line with the intercept $A$ given by eq 4 and slope $B$ given by eq 5 , without regard to differences in molecular weights of the samples. The plots are shown in Figure 4(B) for EP-n-octane system and in Figure 5(B) for EP- $n$-hexane system. In Figures $4(\mathrm{~A})$ and $5(\mathrm{~B})$, relation between $1 / T_{\mathrm{m}}^{\mathrm{g}}$ and $\ln V_{2}$, plotted by the following equation of Eldridge and Ferry, ${ }^{21}$ is also shown in order to compare with the plots of eq 3 .

$$
\ln V_{2}=K_{1}+\frac{\Delta H_{\mathrm{m}}^{\mathrm{g}}}{R} \frac{1}{T_{\mathrm{m}}^{\mathrm{g}}}
$$

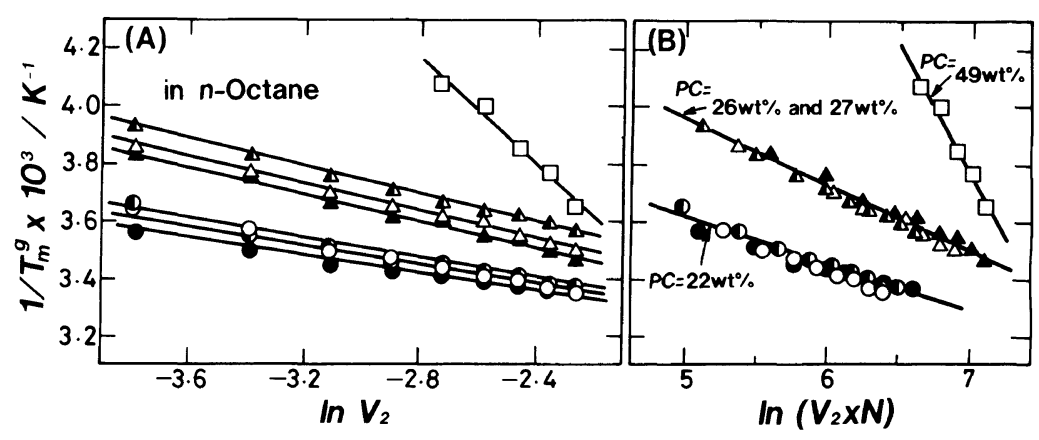

Figure 4. Plot of $1 / T_{\mathrm{m}}^{\mathrm{g}}$ vs. $\ln V_{2}$ (A: Eldridge-Ferry's plot by eq 7), and of $1 / T_{\mathrm{m}}^{\mathrm{g}} v s . \ln V_{2} N$ (B: Takahashi-Nakamura-Kagawa's plot by eq 3) for EP- $n$-octane gels. The ordinate $\left(1 / T_{\mathrm{m}}^{\mathrm{g}}\right)$ of each graph has the same scale and symbols in each graph are the same as those in Figure 2. 


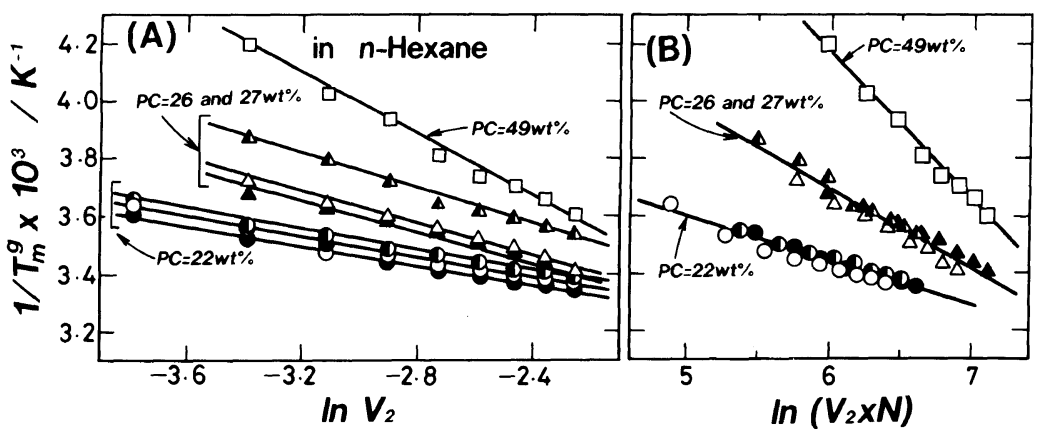

Figure 5. Plot of $1 / T_{\mathrm{m}}^{\mathrm{g}} v s . \ln V_{2}$ according to eq 7 , and of $1 / T_{\mathrm{m}}^{\mathrm{g}} v s . \ln V_{2} N$ according to eq 3 for $\mathrm{EP}-n$-hexane gels. Symbols are the same as those in Figure 2.

$$
\left(\text { or } 1 / T_{\mathrm{m}}^{\mathrm{g}}=K_{2}+\frac{R}{\Delta H_{\mathrm{m}}^{\mathrm{g}}} \ln V_{2}\right)
$$

where $K_{1}$ and $K_{2}$ are the constants and $\Delta H_{\mathrm{m}}^{\mathrm{g}}$ is the enthalpy change for formation of one mole of junction points. As seen in Figures 4(A) and 5(A), a linear relationship is obtained between $1 / T_{\mathrm{m}}^{\mathrm{g}}$ and $\ln V_{2}$ for each sample and thus the concentration dependence of $T_{\mathrm{m}}^{\mathrm{g}}$ can be represented phenomenologically by this type of plot. However, useful information regarding the effect of propylene content on $T_{\mathrm{m}}^{\mathrm{g}}$ can not be obtained pronouncedly from eq 7 .

Whereas in Figures 4(B) and 5(B), a common straight line is constructed for samples with similar $P C$. Accordingly, the effect of $P C$ on $T_{\mathrm{m}}^{\mathrm{g}}$ is very clear as compared with the plots of eq 7. As a whole, the Takahashi theory gives three lines corresponding to $P C=49 \mathrm{wt} \%, 26$ and $27 \mathrm{wt} \%$, and $22 \mathrm{wt} \%$ in both solvents. It is, therefore, obvious from the results in Figures 4(B) and 5(B) that eq 3 represents well $T_{\mathrm{m}}^{\mathrm{g}}$ of the EP gels as a function of $V_{2}, N$, and $B^{\prime}$. As the Takahashi theory treats sol $\rightarrow$ gel transition as crystallization (i.e., formation of crystalline junctions) and gel $\rightarrow$ sol transition as melting of crystalline junctions in a diluent, analysis of eq 3 yields the junction point size in the EP gels.

Estimations of Crystalline Junction Size $\zeta$ and End Interfacial Free Energy $\sigma_{\mathrm{ec}}$

Since the Takahashi theory includes two unknown parameters of $\zeta$ and $\sigma_{\mathrm{ec}}$, these pa- rameters can not be calculated directly from eq 3. So, the following procedures were taken in this study. The intercept $A$ and slope $B$ given by eq 4 and 5 were determined experimentally for each sample from the method of least squares of the plots of $1 / T_{\mathrm{m}}^{\mathrm{g}}$ vs. $\ln V_{2} N$ according to eq 3 . While, by combining eq 4 with eq $5, \zeta$ and $\sigma_{\mathrm{ec}}$ are written as follows, with the intercept $A$ and slope $B$ :

$$
\begin{gathered}
\zeta=\frac{A}{B} \frac{R}{\Delta h_{\mathrm{u}} / T_{\mathrm{m}}^{0}+R V_{\mathrm{A}} / V_{1}-R \cdot \ln X_{\mathrm{A}}} \\
\sigma_{\mathrm{ec}}=\frac{\zeta \Delta h_{\mathrm{u}}+\zeta B^{\prime} V_{\mathrm{A}}+R / B}{2}
\end{gathered}
$$

Accordingly, if we know the values of $\Delta h_{u}, T_{\mathrm{m}}^{0}$, $V_{\mathrm{A}}, V_{1}, X_{\mathrm{A}}$, and $B^{\prime}$ involved in the right-hand sides of eq 8 and $9, \zeta$ and $\sigma_{\mathrm{ec}}$ can be calculated.

In this study, the following numerical values were used ${ }^{17}$ : heat of fusion of crystalline sequences per repeating unit $\left(\left[\mathrm{CH}_{2}-\mathrm{CH}_{2}\right]\right)$, $\Delta h_{\mathrm{u}}=8026 \mathrm{~J} \mathrm{~mol}^{-1}$; equilibrium melting temperature of polyethylene, $T_{\mathrm{m}}^{0}=418.6 \mathrm{~K}$; molar volume of crystalline unit $\left(\left[\mathrm{CH}_{2}-\mathrm{CH}_{2}\right]-\right)$, $V_{\mathrm{A}}=28 \mathrm{~cm}^{3} \mathrm{~mol}^{-1}$. While, molar volume $V_{1}$ of each solvent was determined from its density measurement using a pycnometer. The mole fraction of crystallizable unit $X_{\mathrm{A}}$ in copolymer chains was calculated using the following equation assuming that propylene units were rejected from a crystalline junction:

$$
X_{\mathrm{A}}=1-0.01 \times P C
$$


Table II. Estimated values of $\zeta^{\mathbf{a}}$

\begin{tabular}{|c|c|c|c|c|c|c|c|c|}
\hline \multirow{2}{*}{ Sample } & \multirow{2}{*}{$\frac{P C}{\mathrm{~mol} \%}$} & \multirow{2}{*}{$X_{\mathrm{A}}$} & \multicolumn{6}{|c|}{$\zeta$} \\
\hline & & & in $\mathrm{CS}_{2}$ & in Cyclopentane & in $n$-Hexane & in $n$-Octane & in Toluene & Average \\
\hline EP-17 & 16 & 0.84 & 12.1 & 10.7 & 9.7 & 9.4 & 12.17 & \\
\hline EP-19 & 16 & 0.84 & 10.4 & 10.1 & 10.7 & 9.4 & 11.5 & 11 \\
\hline EP-21 & 16 & 0.84 & 13.9 & 12.0 & 9.4 & 12.4 & 11.2 & \\
\hline EP-22 & 19 & 0.81 & 10.5 & 8.7 & 6.7 & 8.0 & 9.87 & \\
\hline EP-28 & 20 & 0.80 & 9.7 & 8.6 & 7.1 & 8.0 & 9.8 & 9 \\
\hline EP-35 & 20 & 0.80 & 9.8 & 8.6 & 7.9 & 8.1 & 8.9 & \\
\hline EP-38 & 39 & 0.61 & 6.3 & 4.8 & 4.6 & 3.7 & 6.9 & 5 \\
\hline
\end{tabular}

a $P C$, propylene content; $X_{\mathrm{A}}$, mole fraction of crystalline units; $\zeta$, length of crystallite in number of ethylene units.

where $P C$ is the propylene content in $\mathrm{mol} \%$. The cohesive energy density $B^{\prime}$ was estimated from osmotic pressure measurements using eq 2.

The junction size $\zeta$ in number of ethylene units per crystalline sequence estimated for each sample-solvent system is listed in Table II. Values of $\zeta$ in $\mathrm{CS}_{2}$, cyclopentane, and toluene which were used in the previous study ${ }^{12}$ are calculated in this study, and are summarized in the same table. $\zeta$ shows approximately the same magnitude in the samples with similar $P C$, independently of differences in solvents: $\zeta \simeq 11$ for the group with $P C=16 \mathrm{~mol} \%$ (22wt\%); $\zeta \simeq 9$ for $P C=19$ and $20 \mathrm{~mol} \%(26$ and $27 \mathrm{wt} \%) ; \zeta \simeq 5$ for $P C=39 \mathrm{~mol} \% \quad(49$ wt $\%)$, as listed in the last column of Table II. Thus, $\zeta$ decreases with increasing $P C$. In other words, the junction size in number of ethylene units becomes small with increase in methyl branches which disturb considerably crystallization.

Interfacial free energy $\sigma_{\mathrm{ec}}$ is the excess free energy (against perfectly crystalline polyethylene with regularly ordered interface) of each crystalline sequence which emerges from the $\langle 001\rangle$ basal plane of the crystallite. ${ }^{22,23}$ As seen in Table III, values of $\sigma_{\text {ec }}$ determined for EP-17 and EP-22 gels are $13.8-15.4 \mathrm{~kJ} \mathrm{~mol}^{-1}$, and thus do not change widely in the samples
Table III. Values of $B^{\prime}$ and $\sigma_{\mathrm{ec}}^{\mathrm{a}}$

\begin{tabular}{|c|c|c|c|}
\hline \multirow{2}{*}{ Sample } & \multirow{2}{*}{ Solvent } & $B^{\prime}$ & $\sigma_{\mathrm{ec}}$ \\
\hline & & $\mathrm{J} \mathrm{cm}^{-3}$ & $\mathrm{~kJ} \mathrm{~mol}^{-1}$ \\
\hline EP-17 & Toluene & 9.61 & 14.7 \\
\hline EP-17 & $n$-Octane & 5.18 & 15.4 \\
\hline EP-22 & Toluene & 10.8 & 13.8 \\
\hline EP-22 & $n$-Hexane & 6.98 & 13.9 \\
\hline EP-22 & $n$-Octane & 4.51 & 15.0 \\
\hline
\end{tabular}

${ }^{a} B^{\prime}$, cohesive energy density; $\sigma_{\mathrm{ec}}$, end interfacial free energy per crystalline sequence.

used here where the differences in molecular weights are not so large.

It is well known that there are generally three models for the interfacial structure of lamellar crystals crystallized from the melt ${ }^{24}$ : the regular model with the same thickness of lamellar height; the irregular model with different thicknesses of lamellar height; the switchboard model in which a non-ordered amorphous layer is present on each side of the lamellae. An ethylene-propylene copolymer is expected to crystallize into the following forms due to content of comonomer units: defect lamella containing folded structure in case of a little content of propylene units; small folded structure; fringed micelle-type structure in case of much content of propylene units randomly. ${ }^{8}$ 
The range of crystallite sizes and a diversity of interfacial structures as well as properties were studied by Mandelkern et al. ${ }^{22}$ Interfacial free energies of melt-crystallized polyethylenes and of polyethylenes crystallized from dilute solutions have been measured by many workers $^{23,25-28}$ in order to discuss the correlation between interfacial structure and values of $\sigma_{\mathrm{ec}}$. Schultz et al. ${ }^{28}$ measured $\sigma_{\mathrm{ec}}$ of melt-crystallized linear polyethylene fractions of Marlex 6009 as a function of molecular weight (viscosity-average molecular weight), and investigated the correlation between $\sigma_{\mathrm{ec}}$ and molecular weight with the aid of the data measured by Mandelkern et al. ${ }^{27}$ According to their data, values of $\sigma_{\mathrm{ec}}$ were scattered and depended on molecular weight as shown by a shaded region in Figure 6: As the molecular weight of linear polyethylene fraction increased up to and including 56000, there was a significant increase in the crystallite interfacial free energy; For the higher molecular weights, a further slight increase in the values of $\sigma_{\mathrm{ec}}$ was observed but the relative change was not large. ${ }^{27}$ While, Anderson ${ }^{25}$ studied internal morphologies of isothermally bulk-crystallized

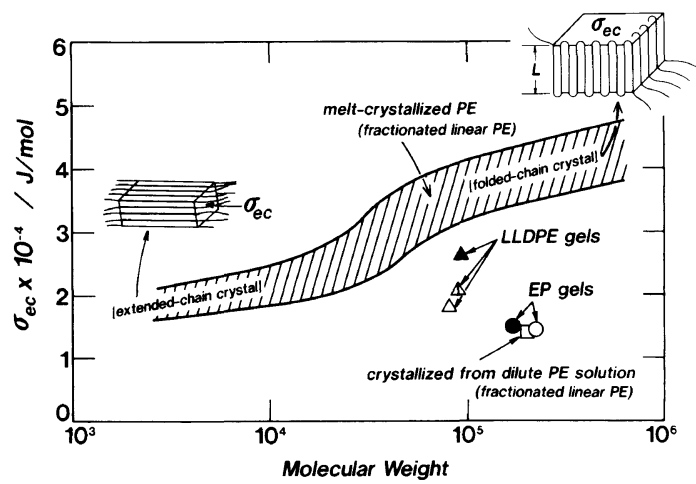

Figure 6. Correlation between end interfacial free energy $\sigma_{\text {ec }}$ and molecular weight: shaded region, data of Schultz et al. $^{28}$ and Mandelkern et $a l .,{ }^{27}$ and morphologies of crystals proposed by Anderson ${ }^{25} ; \Delta, \triangle$, and $\triangle$, data obtained from ethylene-1-octene, ethylene-4-methyl-1pentene, and ethylene-1-butene copolymer gels in $o$-xylene, respectively $^{29}$; and $\bigcirc$, data obtained from EP-17 and EP-22 gels in toluene (this experiment), respectively; $\square$, data of Jackson and Mandelkern. ${ }^{23}$ linear polyethylene fractions of Marlex 50 as a function of molecular weight. According to his results, the lower molecular weight fractions (less than $c a .1 \times 10^{4}$ ) were observed to crystallize into extended-chain lamellae; On the contrary, with increasing molecular weight, folded-chain lamellae were crystallized though the detailed structure was not clear whether the lamellae were regularly folded or not. This morphological change according to molecular weight is shown schematically in Figure 6.

Values of $\sigma_{\mathrm{ec}}$ estimated for crystalline junctions in EP gels (EP-17 and EP-22 in toluene) are plotted against $\bar{M}_{w}$ as seen in Figure 6. Moreover, data of linear low-density polyethylene(LLDPE)- $O$-xylene gels reported in our previous study ${ }^{29}$ and of polyethylene crystallized from dilute solution (in xylene) measured by Jackson and Mandelkern ${ }^{23}$ are plotted in the figure. As a whole, values of $\sigma_{\mathrm{ec}}$ in EP and LLDPE gels formed from moderately concentrated solutions are lower than those in melt-crystallized polyethylenes. The magnitude of $\sigma_{\mathrm{ec}}$ in EP-toluene gels is very close to that of polyethylene crystals formed from dilute solution, ${ }^{23}$ and also corresponds to the data in melt-crystallized polyethylenes with lower molecular weights than $c a .1 \times 10^{4}$ where extended-chain lamellae are crystallized. ${ }^{25}$ According to Mandelkern, ${ }^{23}$ crystals formed from dilute solution would have a mildly disordered interface. Comparing the magnitude of $\sigma_{\mathrm{ec}}$ obtained in the present systems with that obtained by Jackson and Mandelkern, ${ }^{23}$ and further, taking account of the result obtained for bulk-crystallized EP copolymer by Strate, ${ }^{1}$ crystalline junctions in EP gels are not at least considered to be regularly folded-chain crystallites at the interface such as isothermally melt-crystallized single-crystals of linear polyethylenes, but are expected to be fringed micelle-like morphology, particularly for a sample with high content of propylene such as EP-38. 
Crystallite Size D Estimated from X-Ray Diffraction

Crystallite size $D$ in EP gel was determined from X-ray diffraction pattern and it was compared with the junction point size $\zeta$ evaluated from gel-melting temperatures using the Takahashi theory. The crystalline particle size $D$ was calculated using the following Scherrer equation ${ }^{30}$ :

$$
D=\frac{0.9 \lambda}{\left[S_{\mathrm{c}} / H_{\text {max }}\right] \cdot \cos \theta}
$$

where $\lambda$ is the $\mathrm{X}$-ray wavelength, $S_{\mathrm{c}}$ is the integrated scatter intensity from crystallites (i.e., area of the crystalline scattering curve), $H_{\text {max }}$ is the maximum scatter intensity (height), and $\theta$ is the Bragg angle at $H_{\max }$.

A crystalline scattering in the total diffraction pattern of an EP gel was separated from an amorphous scattering by the profile fitting method using the quasi-Voigt function $V(2 \theta)$. This function is widely utilized for estimating a profile of $\mathrm{X}$-ray diffraction pattern, and is written as follows ${ }^{31}$ :

$$
V(2 \theta)=n \cdot I_{\mathrm{G}}+(1-n) \cdot I_{L}
$$

with

$$
\begin{aligned}
I_{\mathrm{G}}= & K(2 / W)[(\ln 2) / \pi]^{1 / 2} \\
& \times \exp \left[-4(\ln 2)\left(2 \theta-\theta_{x}\right)^{2} / W^{2}\right]
\end{aligned}
$$

$$
I_{\mathrm{L}}=K \frac{2}{\pi W\left[1+4\left(2 \theta-\theta_{x}\right)^{2} / W^{2}\right]}
$$

where $I_{\mathrm{G}}$ is the Gauss function, $I_{\mathrm{L}}$ is the Lorentz function, $n$ is the mixing parameter of each function, which varies from 0 to $1,2 \theta$ is the diffraction angle, $K$ is the fitting parameter, $W$ is the half-width of diffraction peak, and $\theta_{x}$ is the Bragg angle.

The best fit of eq 12 to the observed X-ray patterns was carried out varying the parameters $n, K, W$, and $\theta_{x}$ in eq $12-14$ by using a computer equipped with a $X Y$-plotter. A crystalline scattering thus separated from an amorphous scattering is illustrated in Figure 7. From the area $S_{\mathrm{c}}$ and maximum height $H_{\max }$ of crystalline scattering curve in this figure, the crystallite size $D$ was calculated using eq 11 and the values of $D$ are listed in Table IV. In the table, $\zeta$ is the length of crystalline sequence in number of ethylene units estimated from eq 8 , while $\zeta^{*}$ is the length of crystalline sequence calculated with the assumption that $\zeta$ segments in the crystalline junction are fully extended chains. Further, degree of crystallinity $X_{\mathrm{c}}$ was determined from the crystalline scattering area $S_{\mathrm{c}}$ and amorphous scattering area $S_{\mathrm{a}}$ shown in Figure 7 according to the ordinary method. ${ }^{32}$ Values of $X_{c}$ are summarized in Table IV together with those determined from DSC measurements. ${ }^{12}$ A comparison of crystallinity
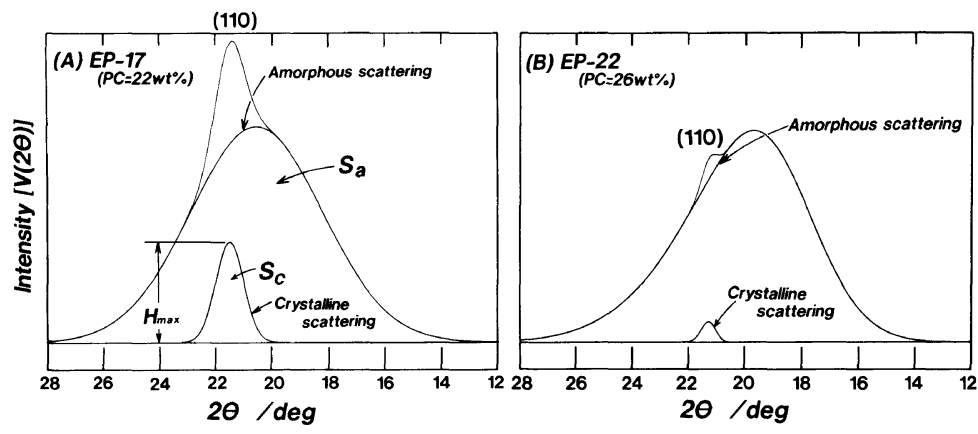

Figure 7. Estimation of crystalline scattering curve from the total X-ray diffraction pattern observed for dried gel film ${ }^{12}$ using the quasi-Voigt function of eq 12: (A), dried gel film of EP-17- $\mathrm{CS}_{2}$ system with concentration $C=6 \mathrm{~g} / 100 \mathrm{~cm}^{3} ;$ (B), dried gel film of EP-22-CS $C_{2}$ system with $C=6 \mathrm{~g} / 100 \mathrm{~cm}^{3} ; S_{\mathrm{c}}$ and $S_{\mathrm{a}}$, areas of crystalline and amorphous scattering curves, respectively. 
Table IV. The size of crystalline junction estimated from the Takahashi theory and crystallite size determined by $\mathrm{X}$-ray diffraction ${ }^{\mathrm{a}}$

\begin{tabular}{|c|c|c|c|c|c|}
\hline \multirow{3}{*}{ System } & \multirow{3}{*}{$\zeta$} & \multirow{3}{*}{$\frac{\zeta^{*}}{\mathrm{~nm}}$} & \multirow{3}{*}{$\frac{D}{\mathrm{~nm}}$} & \multicolumn{2}{|c|}{$X_{\mathrm{c}}$} \\
\hline & & & & from X-ray & from DSC \\
\hline & & & & $\%$ & $\%$ \\
\hline EP-17 in $\mathrm{CS}_{2}$ & 12.1 & 3.6 & $5.7 \pm 0.5$ & 9.1 & 6.4 \\
\hline $\mathrm{EP}-22$ in $\mathrm{CS}_{2}$ & 10.5 & 3.1 & $4.2 \pm 0.5$ & 2.0 & 1.6 \\
\hline EP-38 in $\mathrm{CS}_{2}$ & 6.3 & 1.8 & - & - & 0.13 \\
\hline
\end{tabular}

a $\zeta$, length of crystalline junction in number of ethylene units; $\zeta^{*}$, length of crystalline junction calculated by assuming $\zeta$ segments in the crystallite to be fully extended chains; $D$, crystallite size determined from X-ray diffraction of lyophilized gel film; $X_{\mathfrak{c}}$, degree of crystallinity of lyophilized gel film.

values from X-ray and DSC measurements shows approximately good agreement for each sample. In this respect, the present analysis of $\mathrm{X}$-ray diffractions was carried out precisely.

As seen in Table IV, the value of $\zeta^{*}$ estimated for each sample is considered to be reasonable order as compared with the size $D$. However, $\zeta *$ seems to show somewhat lower value than $D$. The underestimation for $\zeta^{*}$ may be caused by the following fact: The Takahashi theory of melting temperature depression due to copolymerization treats the case where a comonomer unit (i.e., propylene unit in case of the present samples) is excluded from a crystalline junction. According to the results of X-ray diffractions by Swan, ${ }^{10}$ however, the crystalline lattice of ethylene-propylene copolymer can accommodate low content of methyl branches. From this point, $\zeta^{*}$ obtained in this study may be underestimated; In this study, further, the mole fraction of crystallizable unit $X_{\mathrm{A}}$ was determined from eq 10 assuming that propylene units with methyl branches were not incorporated into a crystalline junction. Therefore, if more accurate treatment will be found for the estimation of $X_{\mathrm{A}}, \zeta^{*}$ may be determined more precisely.

Strate et al. ${ }^{1,9}$ studied crystallinity of bulk-crystallized EP copolymer with $c a$. $40 \mathrm{~mol} \%$ propylene from X-ray diffractions, and reported that about five ethylene units could be crystallized when the copolymer was annealed sufficiently for several days. In our results of EP-38-organic solvent gels, whose sample $(P C=39 \mathrm{~mol} \%)$ is comparable with the copolymer used by Strate et al. since the propylene content is similar to each other, average size of crystalline junction $\zeta$ was estimated to be $c a .5$ as listed in the last column of Table II. Accordingly, the magnitude of $\zeta$ in EP-38 gels is quite close to the data estimated by Strate et al., though their result was obtained in the bulk.

According to this study, a junction point of three-dimensional network structure in EP gels is considered to be fringed micelle-type crystallite in which $\rho$ crystalline sequences with $\zeta$ segments of ethylene units are aggregated. In the samples used here, sequence distribution of ethylene and propylene exists along EP chains. There exists locally the loci where ethylene sequence is rich, at which $\zeta$ segments (probably including a few units of propylene) may gather together to make a crystalline junction with cooling, as illustrated schematically in Figure 8, confining amorphous chains and solvent among these crystalline junctions.

Unknown quantities which must be determined are still present: One is the multifunctionality $\rho$ of a crystalline junction; The other is the lateral surface free energy $\sigma_{\mathrm{u}}$ of the junction point per repeating unit. The total surface free energy is equal to $2 \zeta \sigma_{u}(\pi \rho)^{1 / 2}$, if the junction point morphology is cylindrical 


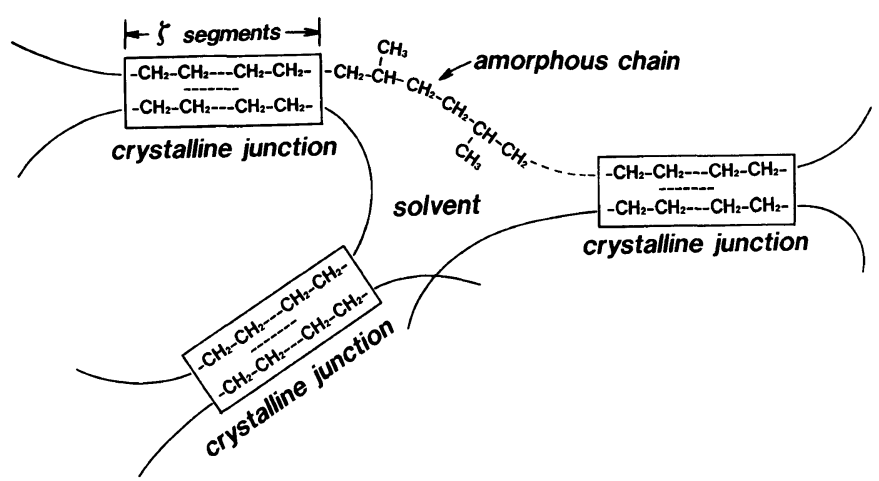

Figure 8. Schematic drawing of junction point model in EP-organic solvent gels.

form as shown in Figure 3. However, the values of $\rho$ and $\sigma_{\mathrm{u}}$ can not be determined directly from the Takahashi theory. These problems are left for future study.

\section{CONCLUSIONS}

The present study clarifies the following results for the structure and sizes of crystalline junctions formed in EP random copolymerorganic solvent gels:

1. EP random copolymers in $n$-hexane and $n$-octane also convert to thermally reversible gels from moderately concentrated solutions similarly to $\mathrm{CS}_{2}$, toluene, and cyclopentane reported previously. ${ }^{12}$ The gel formation in organic solvents is one of the general properties of the EP copolymers.

2. Gel-melting temperature $T_{\mathrm{m}}^{\mathrm{g}}$ depends strongly on the comonomer content: $T_{\mathrm{m}}^{\mathrm{g}}$ lowers exceedingly with increasing propylene content, without regard to differences in molecular weights; Effect of the propylene content on $T_{\mathrm{m}}^{\mathrm{g}}$ can be represented well by the thermodynamic theory derived by Takahashi.

3. Junction points in EP gels are crystallites and a fringed micelle-type structure is appropriate for the crystalline junctions.

4. The size of crystalline junction $\zeta$ (i.e., number of ethylene units) evaluated from the Takahashi theory depends on the comonomer content: The size $\zeta$, which is reasonable order as compared with the crystallite size obtained from X-ray diffractions, decreases with increasing methyl branches due to propylene.

Acknowledgments. The authors express their sincere appreciation to Professor Dr. Akira Takahashi of the Faculty of Engineering, Mie University, for his useful suggestions and discussion. Thanks are also due to Professor Dr. Tetsuzo Ito of Kanagawa Institute of Technology, for the discussion in analysis of $\mathrm{X}$-ray diffractions.

\section{REFERENCES}

1. G. V. Strate, "Ethylene-Propylene Elastomers," in "Encyclopedia of Polymer Science and Engineering," Vol. 6, 2nd ed, H. F. Mark, N. M. Bikales, C. G. Overberger, G. Menges, and J. I. Kroschwitz, Ed., Wiley-Interscience, New York, N.Y., 1986, p 522.

2. E. A. Cole and D. R. Holmes, J. Polym. Sci., 46, 245 (1960).

3. M. J. Richardson, P. J. Flory, and J. B. Jackson, Polymer, 4, 221 (1963).

4. P. J. Holdsworth and A. Keller, J. Polym. Sci., B, 5, 605 (1967).

5. P. J. Holdsworth and A. Keller, Makromol. Chem., 125, 70 (1969).

6. D. Bodily and B. Wunderlich, J. Polym. Sci., A-2, 4, 25 (1966).

7. J. F. Jackson, J. Polym. Sci., A, 1, 2119 (1963).

8. G. V. Strate and Z. W. Wilchinsky, J. Polym. Sci., $A-2,9,127$ (1971).

9. F. P. Baldwin and G. V. Strate, Rubber Chem. Technol., 45, 709 (1972).

10. P. R. Swan, J. Polym. Sci., 56, 409 (1962).

11. a) H. Matsuda, T. Inoue, M. Okabe, and T. Ukaji, Polym. J., 19, 323 (1987); b) M. Okabe, K. Mitsui, 
and H. Matsuda, Kobunshi Ronbunshu, 46, 681 (1989); c) M. Okabe, K. Mitsui, F. Sasai, and H. Matsuda, Polym. J., 21, 313 (1989); d) H. Matsuda, R. Kashiwagi, and M. Okabe, Polym. J., 20, 189 (1988).

12. M. Okabe, K. Mitsui, H. Uranaka, M. Takahashi, and H. Matsuda, Polym. J., 24, 653 (1992).

13. A. Takahashi, T. Nakamura, and I. Kagawa, Polym. J., 3, 207 (1972).

14. A. Takahashi and T. Kato, Res. Rep. Fac. Eng. Mie Univ., 1, 97 (1976).

15. For example, J. F. Rabek, "Thermal Analysis of Polymers," in "Experimental Methods in Polymer Chemistry," Wiley-Interscience, New York, N.Y., 1980, Chapter 34.

16. B. Wunderlich and C. M. Cormier, J. Polym. Sci., $A-2,5,987$ (1967).

17. A. Takahashi, M. Sakai, and T. Kato, Polym. J., 12, 335 (1980).

18. For example, P. J. Flory, "Principles of Polymer Chemistry," Cornell University Press, Ithaca, N.Y., 1953, Chapters VII and XII.

19. P. J. Flory, J. Chem. Phys., 17, 223 (1949).

20. L. Mandelkern, J. Appl. Phys., 26, 443 (1955).

21. J. E. Eldridge and J. D. Ferry, J. Phys. Chem., 58,
992 (1954).

22. L. Mandelkern, A. L. Allou, Jr., and M. Gopalan, J. Phys. Chem., 72, 1, 309 (1968).

23. J. F. Jackson and L. Mandelkern, Macromolecules, 1, 546 (1968).

24. For example, J. F. Rabek, "Overview of Polymer Morphology," in "Experimental Methods in Polymer Chemistry," Wiley-Interscience, New York, N.Y., 1980, Chapter 26.

25. F. R. Anderson, J. Appl. Phys., 35, 64 (1964).

26. L. Mandelkern, J. Polym. Sci., C, 15, 129 (1966).

27. L. Mandelkern, J. M. Price, M. Gopalan, and J. G. Fatou, J. Polym. Sci., A-2, 4, 385 (1966).

28. J. M. Schultz, W. H. Robinson, and G. M. Pound, J. Polym. Sci., A-2, 5, 511 (1967).

29. M. Okabe, M. Isayama, and H. Matsuda, J. Appl. Polym. Sci., 30, 4735 (1985).

30. For example, B. D. Cullity, "Elements of X-Ray Diffraction," Addison-Wesley, Reading, Massachusetts, 1956.

31. G. K. Wertheim, M. A. Butler, K. W. West, and D. N. E. Buchanan, Rev. Sci. Instrum., 45, 1369 (1974).

32. A. Weidinger and P. H. Hermans, Makromol. Chem., 50, 98 (1961). 